\title{
Physiology of deletion mutants in the anaerobic $\beta$-myrcene degradation pathway in Castellaniella defragrans
}

Frauke Lüddeke, Aytac Dikfidan and Jens Harder ${ }^{*}$

\begin{abstract}
Background: Monoterpenes present a large and versatile group of unsaturated hydrocarbons of plant origin with widespread use in the fragrance as well as food industry. The anaerobic $\beta$-myrcene degradation pathway in Castellaniella defragrans strain 65Phen differs from well known aerobic, monooxygenase-containing pathways. The initial enzyme linalool dehydratase-isomerase Idi/LDI catalyzes the hydration of $\beta$-myrcene to (S)-(+)-linalool and its isomerization to geraniol. A high-affinity geraniol dehydrogenase geoA/GeDH and a geranial dehydrogenase geoB/ $\mathrm{GaDH}$ contribute to the formation of geranic acid.

A genetic system was for the first time applied for the betaproteobacterium to prove in vivo the relevance of the linalool dehydratase-isomerase and the geraniol dehydrogenase. In-frame deletion cassettes were introduced by conjugation and two homologous recombination events.

Results: Polar effects were absent in the in-frame deletion mutants $C$. defragrans $\Delta / d i$ and $C$. defragrans $\Delta$ geoA. The physiological characterization of the strains demonstrated a requirement of the linalool dehydratase-isomerase for growth on acyclic monoterpenes, but not on cyclic monoterpenes. The deletion of geoA resulted in a phenotype with hampered growth rate on monoterpenes as sole carbon and energy source as well as reduced biomass yields. Enzyme assays revealed the presence of a second geraniol dehydrogenase. The deletion mutants were in trans complemented with the broad-host range expression vector pBBR1MCS-4/di and pBBR1MCS-2geoA, restoring in both cases the wild type phenotype.

Conclusions: In-frame deletion mutants of genes in the anaerobic $\beta$-myrcene degradation revealed novel insights in the in vivo function. The deletion of a high-affinity geraniol dehydrogenase hampered, but did not preclude growth on monoterpenes. A second geraniol dehydrogenase activity was present that contributes to the $\beta$ myrcene degradation pathway. Growth on cyclic monoterpenes independent of the initial enzyme LDI suggests the presence of a second enzyme system activating unsaturated hydrocarbons.
\end{abstract}

Keywords: $\beta$-myrcene, phellandrene, Anaerobic degradation, Geraniol dehydrogenase, Linalool dehydrataseisomerase, Genetic system

\section{Background}

Monoterpenes represent a prominent group of volatile organic compounds (VOC), with an estimated mean global

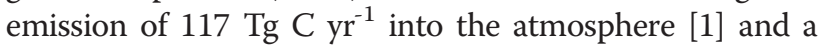
fast photochemical turnover [2]. Especially coniferous plants are considered to be main producers of monoterpenes, e.g. for thermotolerance or for communication

\footnotetext{
* Correspondence: jharder@mpi-bremen.de

Dep. of Microbiology, Max Planck Institute for Marine Microbiology, Celsiusstr. 1, 28359, Bremen, Germany
}

(c) 2012 Lüddeke et al.; licensee BioMed Central Ltd. This is an Open Access article distributed under the terms of the Creative Commons Attribution License (http://creativecommons.org/licenses/by/2.0), which permits unrestricted use, distribution, and reproduction in any medium, provided the original work is properly cited. between plants or the interaction between plants and insects [3-5]. Monoterpenes also enter the soil by the rhizosphere or by rotten leafs [6], where they inhibit growth of microorganisms as well as of seedlings [7-9], but also stimulate the bacterial activity detectable in higher biomass and $\mathrm{CO}_{2}$-production $[5,10,11]$. By definition, monoterpenes possess a carbon skeleton based on two $\mathrm{C}_{5}$ units originating from isopentenyl pyrophosphate (IPP), which is synthesized via the mevalonate (in eukaryotes) or the mevalonate-independent pathway (in prokaryotes and plant plastids) [12-14]. Mainly, plant 
monoterpenes are produced via the latter pathway, but the metabolic cross linkage between both has been reported in several species $[15,16]$.

Monoterpenes are together with sesquiterpenes the major constituents of essential oils. Due to their status they are generally recognized as safe (GRAS) [17] - and their odorous properties, these substances are widespread in the food, cosmetics, flavour and fragrance industry [18]. Monoterpenes are utilized as energy and carbon source by several aerobic microorganisms, a fact known since the 1960s [19-21]. Most reports dealt with Pseudomonas species, e.g. [22-28], but also Bacillus stearothermophilus [29], Rhodococcus erythropolis [30], and Enterobacter cowanii [31] metabolize these hydrocarbons. The microbial degradation of $\alpha$-pinene and limonene, one of the most widespread monoterpenes in nature, involve complex and multiple pathways that comprise in large part oxidation reactions [30,32-34]. In addition these studies revealed the importance of oxygenases, which catalyze hydroxylation reactions with molecular oxygen as co-substrate [35-38].

Under anaerobic conditions, the biochemistry for the activation of these natural abundant alkenes seems to follow a totally different mechanism. The first evidence for the anaerobic degradation of monoterpenes were seven nitrate-reducing enrichment cultures with monoterpenes as sole carbon source [39]. Isolation led to the description of four Alcaligenes defragrans strains, including strain 65Phen isolated with $\alpha$-phellandrene [40]. A taxonomic study transferred these strains in the novel genus Castellaniella within the Alcaligenaceae, as $C$. defragrans [41]. The betaproteobacterium is capable of degrading a broad substrate range of a-, mono-, and bicyclic monoterpenes (Figure 1) [40]. Initial metabolite studies on the anaerobic monoterpene degradation pathway in $C$. defragrans elucidated the demand for a $\mathrm{sp}^{2}$ hybridized $\mathrm{C} 1$-atom as structural prerequisite for monoterpenes utilization [42] as well as the formation of geranic acid as intermediate [43], which is likely degraded on a modified $\beta$-oxidation pathway $[44,45]$. These findings proposed the degradation of $\beta$-myrcene via hydration to linalool, followed by isomerisation to geraniol, and then two oxidations to geranial and to geranic acid [43]. The genes and proteins involved this pathway were recently identified [46,47] (Figure 2). The bifunctional linalool

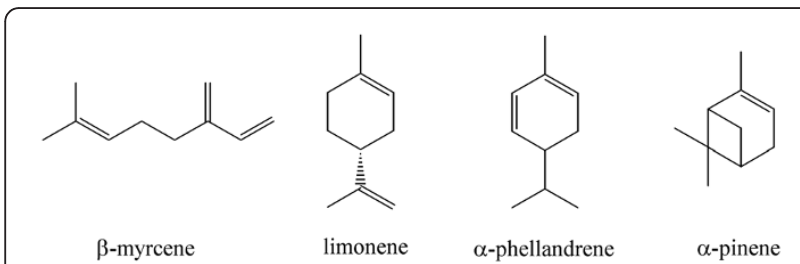

Figure 1 Monoterpene substrate range of $C$. defragrans [40].

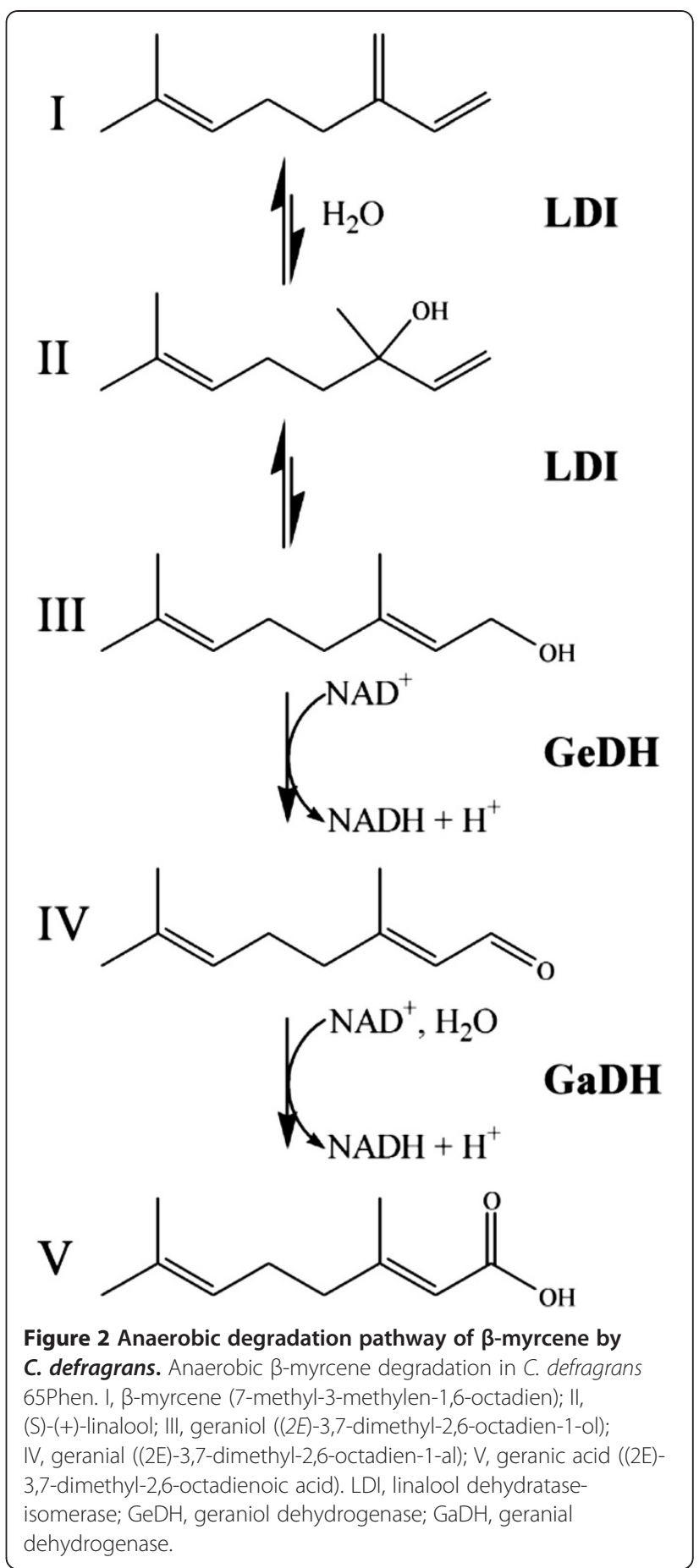

dehydratase-isomerase $l d i / \mathrm{LDI}$ catalyzes the first two steps, the highly enantiospecific hydration of $\beta$-myrcene to $(S)-(+)$-linalool and its isomerisation to geraniol $[46,48]$. Subsequently, two dehydrogenases oxidize the allylalcohol geraniol and geranial. The geraniol dehydrogenase $g e o A / \mathrm{GeDH}$ (E. C. 1.1.1.183) is a member of the medium-chain dehydrogenase/reductase superfamily [49] with high affinity for its substrate geraniol [47]. In vitro studies confirmed the activity of a geranial dehydrogenase 
geoB/GaDH. Both dehydrogenases were expressed in cells growing with monoterpenes [47].

So far, the evidence for the anaerobic $\beta$-myrcene degradation pathway was rather biochemically based on metabolite and enzyme studies. To prove the physiological role in vivo, we created deletion mutants of $C$. defragrans missing the gene $l d i$ and geo $A$, respectively. The previous findings, i.e. the geranic acid formation and the induced dehydrogenase activities, were observed in both acyclic and monocyclic monoterpenes grown cells and suggested the existence of a common degradation pathway. To clarify whether there is one defined metabolic route or multiple pathways present for the anaerobic degradation of monoterpenes in $C$. defragrans, we deleted the initial, $\beta$-myrceneactivating enzyme, the LDI. The deletion of the GeDH was of interest due to the frequent presence of multiple alcohol dehydrogenases in genomes, often with a broad substrate range.

\section{Results and Discussion}

\section{Construction of the in-frame deletion mutant}

\section{C. defragrans $\Delta /$ di and $\Delta g e o A$}

Growth of $C$. defragrans as single colony under denitrifying conditions was achieved on acetate in a defined, solidified medium. A spontaneous mutant strain resistant to rifampicin $(150 \mu \mathrm{g} / \mathrm{ml})$ was obtained showing the phenotype of the wildtype with respect to growth on monoterpenes (Additional file 1: Table S1). Conjugation was established with the broad host range plasmid pBBR1MCS-2, proceeding with a frequency of $1.8 \times 10^{-4}$ transconjugants cell/ donor cells in $8 \mathrm{~h}$ (Additional file 1: Table S2). The plasmid was maintained in C. defragrans. For genomic deletion mutants, we constructed pK19mobsacB $\Delta l d i$ and pK19mobsacB $\Delta g e o A$ that carried the start and stop codon of the ldi (ORF26) or geoA (ORF31) separated by a specific restriction site and the upstream and downstream located regions (Additional file 1: Figure S1). The sequence information was obtained from a $50 \mathrm{~kb}$ contig (Acc. no. FR669447.2) with the following annotation for ORFs adjacent to ldi or geoA: ORF27 as a thioesterase, ORF29 as a putative subunit of cytochrome c oxidase, ORF30 as a secretory protein and ORF32 as a long-chain-fatty-acid CoA ligase, while for ORF25 only hypothetical proteins were found in database queries (Additional file 1: Figure S2). Conjugation and homologous recombination yielded genomic in-frame deletions, with a second recombination frequency of $0.5 \%$ and $1.25 \%$ for the deletion of $l d i$ and of geoA, respectively. Analysis by PCR revealed in the deletion mutants the expected, shortened amplicons with primer pairs spanning the deleted gene in comparison with the wild type (Additional file 1: Figure S3). Polar effects due to the deletion of $l d i$ or geoA were not detected in mRNA analyses (Additional file 1: Figure $\mathrm{S} 4)$. The genes $l d i$ or geoA and their native ribosomal binding site were cloned in the MCS of pBBR1MCS plasmids. Conjugation into $C$. defragrans deletion mutants yielded ampicillin-resistant transconjugants named $C$. defragrans $\Delta$ ldicomp and kanamycin-resistant transconjugants named C. defragrans $\Delta g e o A$ comp.

\section{Physiological characterization of $C$. defragrans $\Delta / d i$}

Under standard culturing conditions for anaerobic, denitrifying growth with $10 \mathrm{mM}$ nitrate and $4 \mathrm{mM}$ cyclic $\alpha$-phellandrene or limonene in 2,2,4,6,6,8,8-heptamethylnonane (HMN), C. defragrans strains 65Phen, $\Delta l d i$, and $\Delta$ ldicomp grew to final OD ranging from 0.25 to 0.35 (Figure 3A, B). C. defragrans strains 65Phen metabolized the acyclic $\beta$-myrcene, but $C$. defragrans $\Delta l d i$ lacking the gene for the $l d i$ failed to grow with this substrate (Figure 3C). The in trans complementation $\Delta l d i$ comp restored the wild type phenotype. These data showed that the LDI is essential for the metabolism of $\beta$-myrcene, but not for the cyclic monoterpenes $\alpha$-phellandrene and limonene.

In previous studies, $\beta$-myrcene as well as $\alpha$ phellandrene supported the formation of geranic acid in cell suspension experiments. The geranic acid pool was 10fold larger in $\beta$-myrcene experiments than with the cyclic monoterpenes $\alpha$-pinene, $\alpha$-phellandrene, and limonene [43]. We assayed the geranic acid pools in C. defragrans mutant strains under nitrate-limited conditions in liquid cultures on $6 \mathrm{mM}$ monoterpene in HMN (Table 1). This metabolite was only detectable in myrcene-grown $C$. defragrans cultures with the ldi either present in the genome or in trans, in concentrations of $8.85 \mu \mathrm{M}$ and $6.61 \mu \mathrm{M}$, respectively. In $\alpha$-phellandrene grown cultures, geranic acid was detectable in media of these $C$. defragrans strains in concentrations of $0.24 \mu \mathrm{M}$ and $0.33 \mu \mathrm{M}$. Geranic acid formation was not detectable in cultures of the mutant lacking the gene ldi. The RPHPLC detection limit was $6.4 \mathrm{nM}$, thus geranic acid formation in $C$. defragrans $\Delta l d i$ was below a thousandth of that in the wild type. Growth on $\alpha$-phellandrene clearly does not involve the formation of geranic acid suggesting the presence of another monoterpene degrading pathway that circumvents the activation of the substrate by LDI as well as geranic acid formation.

Under aerobic conditions microbial biotransformation of (-)-limonene and $\beta$-myrcene revealed the formation of enantiopure (-)-perillyl alcohol, perillyl acid and myrcenic acid [30,50-52]. Anaerobic hydroxylations catalyzed by molybdenum enzymes have been recently reported, e.g. the hydroxylation of ethylbenzene to $(S)$-phenylethanol in Aromatoleum aromaticum [53] and of cholesterol to cholest-1,4-diene-3-one in Sterolibacterium denitrificans [54]. Whether the degradation of cyclic monoterpenes 


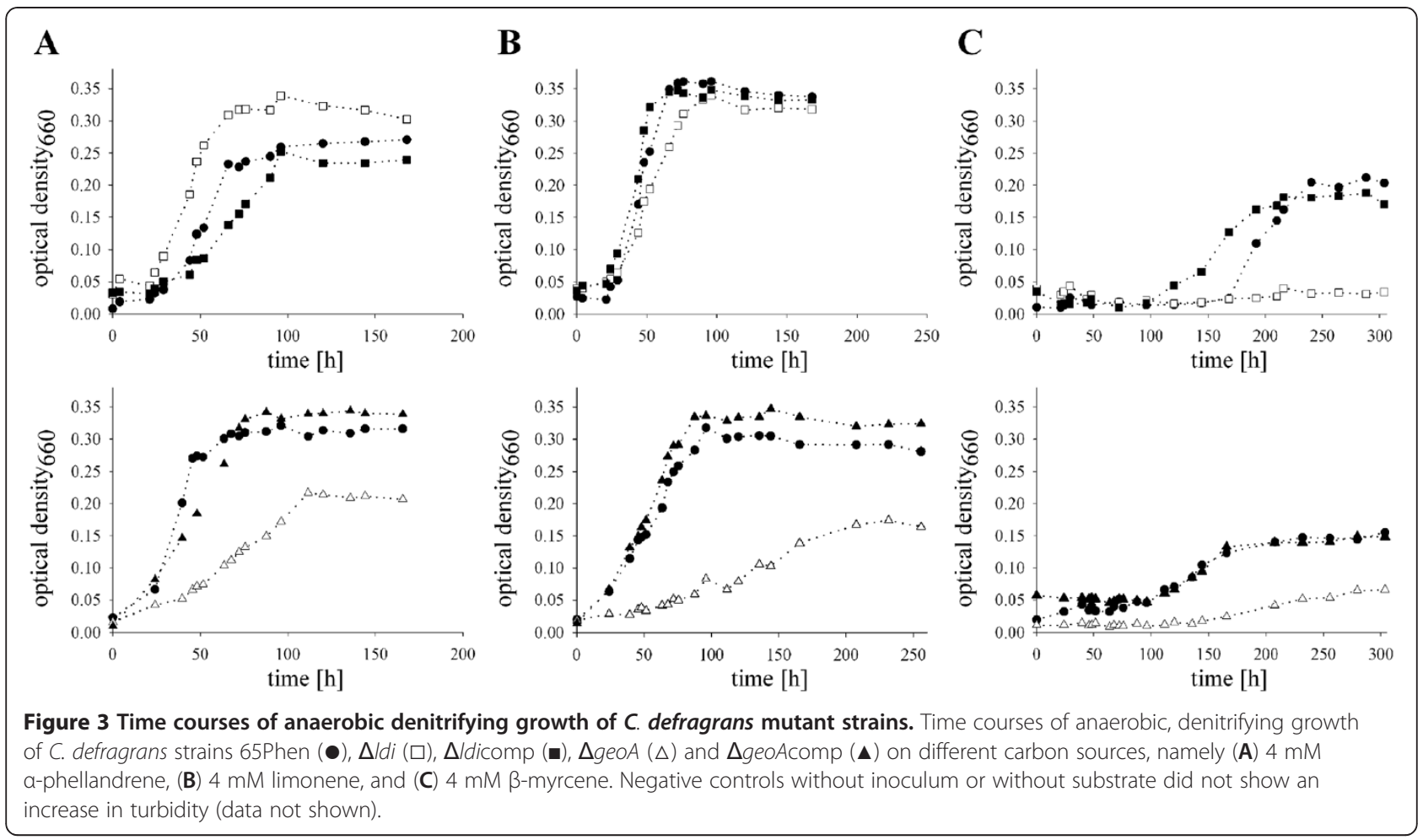

proceeds via a homologue pathway is subjected in ongoing research. To our knowledge, this is the first report on the existence of different activation mechanisms for cyclic and acyclic monoterpenes in one bacterial strain.

\section{Physiological and enzymatic characterization of $C$. defragrans $\triangle g e o A$}

The deletion of geo $A$ resulted in an increased generation time and reduced biomass yields, e.g. on $\alpha$-phellandrene, limonene and $\beta$-myrcene (Figure $3 \mathrm{~A}-\mathrm{C}$, Table 2). Nitrate was completely consumed, but the generation time was always prolonged, e.g. 3.5-fold for $\alpha$-phellandrene. The biomass formed as determined by protein analyses was decreased by $32 \%$ to $48 \%$ in the deletion mutant (Table 2). Most likely, geraniol was oxidized at slower rate in the deletion mutant. This seems to have an

Table 1 Geranic acid pools in cultivation media

\begin{tabular}{lll}
\hline C. defragrans strains & \multicolumn{2}{c}{ Geranic acid concentration $[\mu \mathrm{M}]$} \\
\cline { 2 - 3 } & $\mathbf{a}$-Phellandrene & $\boldsymbol{\beta}$-Myrcene \\
\hline 65Phen (wild type) & $0.24 \pm 0.01$ & $8.85 \pm 0.6$ \\
$\Delta /$ di & n.d. & n.d. \\
$\Delta /$ dicomp & $0.33 \pm 0.24$ & $6.61 \pm 0.19$ \\
$\Delta$ geoA & n.d. & $4.96 \pm 1.58$ \\
$\Delta$ geoAcomp & $0.89 \pm 0.25$ & $11.79 \pm 0.31$
\end{tabular}

C. defragrans cultures were grown in $150 \mathrm{~mL}$ with $6 \mathrm{mM}$ a-phellandrene or $\beta$-myrcene and $10 \mathrm{mM}$ nitrate at $30^{\circ} \mathrm{C}$ and $130 \mathrm{rpm}$. Inoculum size was $1 \%(\mathrm{v} / \mathrm{v})$. Duplicate determination. Detection limit for geranic acid was $6.4 \mathrm{nM}$. n.d. $=$ not detectable. inhibitory effect on the growth due to the known geraniol in vivo toxicity of above $5 \mu \mathrm{M}$ in the aqueous phase [47]. The intracellular geraniol concentrations were below the detection threshold of gas chromatographical analysis, but we observed physiological evidence for increased geraniol pools. In the cultivation system with HMN, 4 mM geraniol stopped monoterpene utilization completely [47]. In the wild type, addition of $16 \mathrm{mM}$ acetate supported growth in the presence of $4 \mathrm{mM}$ geraniol and $20 \mathrm{mM}$ nitrate to an $\mathrm{OD}_{660}$ of $0.15( \pm 0.002$; $\mathrm{n}=2$ ). The deletion mutant $C$. defragans $\triangle g e o A$ also grew after acetate addition, but reached only an $\mathrm{OD}_{660}$ of $0.061( \pm 0.01 ; n=2)$, although both strains consumed the same nitrate amount. In conclusion, $C$. defragans $\triangle g e o A$ reacts more sensitive towards geraniol than the wild type.

The growth phenotype of the wild type was recovered in the mutant strain by complementation with the geo $A$ gene located on a broad-host range plasmid. The in trans complemented mutant $C$. defragrans $\Delta$ geoAcomp revealed physiological characteristics similar to $C$. defragrans 65Phen: growth rate and yield, monoterpene consumption and nitrate reduction were almost identical suggesting that the wild type phenotype was restored by $\mathrm{GeDH}$ constitutively expressed from the plasmid pBBR1MCS-2geoA (Table 2, Figure 3).

The absence of $\mathrm{GeDH}$ was expected to reduce the rate of geranic acid formation. In this study, geranic acid was detected in cultures grown on $6 \mathrm{mM}$ monoterpene in 
Table 2 Physiological properties of $C$. defragrans strains growing with different monoterpenes

\begin{tabular}{|c|c|c|c|c|c|c|c|c|c|}
\hline & \multicolumn{3}{|c|}{ a-Phellandrene } & \multicolumn{3}{|c|}{ Limonene } & \multicolumn{3}{|c|}{$\beta$-Myrcene } \\
\hline & 65Phen & $\Delta g e o A$ & $\Delta g e o A c o m p$ & 65Phen & $\Delta g e o A$ & $\overline{\Delta g e o A c o m p}$ & 65Phen & $\Delta g e o A$ & $\Delta$ geoAcomp \\
\hline $\mathrm{MaxOD}_{660}$ & 0.321 & 0.217 & 0.342 & 0.318 & 0.174 & 0.347 & 0.155 & 0.066 & 0.149 \\
\hline Generation time [h] & 9.8 & 34.9 & 13.5 & 25.4 & 50.8 & 44.9 & 46.9 & 57.1 & 45.8 \\
\hline $\mathrm{NO}_{3}^{-}$consumed $[\mathrm{mM}]$ & 10 & 10 & 10 & 10 & 10 & 10 & 7.3 & 5.8 & 8.1 \\
\hline $\mathrm{NO}_{2}^{-}$formed $[\mathrm{mM}]$ & 0 & 0 & 0 & 0 & 0 & 0.01 & 0.22 & 0 & 0.009 \\
\hline Biomass formed $[\mathrm{g} / \mathrm{L}]$ & 0.34 & 0.23 & 0.32 & 0.35 & 0.22 & 0.35 & 0.14 & 0.08 & 0.17 \\
\hline
\end{tabular}

C. defragrans strains $65 \mathrm{Phen}$ (wild type), $\triangle$ geoA and $\triangle$ geoAcomp were grown under standard conditions at $28^{\circ} \mathrm{C}$ for $280 \mathrm{~h}$ (a-phellandrene, limonene) or for $304 \mathrm{~h}$ ( $\beta$-myrcene) with $4 \mathrm{mM}$ monoterpene (in $\mathrm{HMN}$ ) and $10 \mathrm{mM}$ nitrate. As negative control served a culture without inoculum.

the presence of HMN and $10 \mathrm{mM}$ nitrate (Table 1). Cultures were sampled after nitrate depletion. Geranic acid concentrations of acidified and lysed cultures were $9 \pm 1 \mu \mathrm{M}$ in the medium of the wild type and $12 \pm 1 \mu \mathrm{M}$ in the medium of the complemented mutant, but only $5 \pm 2 \mu \mathrm{M}$ in the medium of $C$. defragrans $\triangle$ geo $A$, thus revealing a limited capacity to form geranic acid in the absence of $\mathrm{GeDH}$.

The $\Delta g e o A$ phenotype has still the capacity to degrade monoterpenes, an indication for the presence of another alcohol dehydrogenase that catalyzes the geraniol oxidation. Thus, we tested the GeDH activity spectrophotometrically in cell-free, cytosolic extracts of C. defragrans strains 65Phen, $\triangle g e o A$ and $\triangle g e o A$ comp. Under standard conditions, with $0.8 \mathrm{mM}$ geraniol as substrate and identical protein concentrations in the assay, the geraniol oxidation rates were $5.8 \mathrm{nkat}^{\mathrm{mg}^{-1}}$ protein for $C$. defragrans 65Phen and $1.05 \mathrm{nkat}^{\mathrm{mg}^{-1}}$ protein for $C$. defragrans $\triangle g e o A$. Complementation restored the activity to 9.4 nkat $\mathrm{mg}^{-1}$ protein in $C$. defragrans $\Delta$ geoAcomp. The in vivo concentration of geraniol inside the cell is expected to be in the micromolar range [47]. The GeDH activity in the extracts of $C$. defragrans $\triangle g e o A$ catalyzed the reaction with a high affinity, the apparent concentration for half-maximal rate was below $10 \mu \mathrm{M}$ geraniol (Figure 4). This indicated an activity of the second alcohol dehydrogenase at physiological conditions.

In summary, the presented data argue for a reduced geraniol flux to geranic acid in the metabolism of the deletion mutant. We suggest that a geraniol accumulation or increased pools of metabolites derived from geraniol on other pathways cause a reduced growth rate as indicated by prolonged generation time, decreased biomass production, and reduced geranic acid formation. The accumulation of a toxic intermediate in monoterpene catabolism causing reduced growth rate has also been seen for deletion mutants of P. putida M1 in ß-myrcene degradation [24,55]. Accumulation of geraniol is known to be toxic for cells: due to its hydrophobic properties it can integrate into bacterial membranes causing disintegrations followed by failure of the proton motive force $[56,57]$.
The presence of several ADHs in a genome is not unusual. In microorganisms, alcohol dehydrogenases possess a wide variety of substrate specificities and are involved in different physiological functions [58]. For various $\mathrm{ADHs}$ deficient mutants, retarded growth on the prevailing substrate and reduced $\mathrm{ADH}$ activity was observed [59-61]. Also in plants the existence of additional ADHs capable of oxidizing geraniol was suggested [62].

\section{Conclusions}

We developed a genetic system for Castellaniella defragrans and constructed in-frame deletion mutants that allows for insights into the physiology of the anaerobic degradation of monoterpenes.

C. defragrans $\triangle g e o A$ lacking the gene for a geraniol dehydrogenase was physiologically analysed. The geo $A$ deficient strain exhibited reduced growth on monoterpenes and slower geraniol oxidation rates in soluble extracts, in comparison to the wild type. The original phenotype was restored in trans with an episomal geo $A$ in the $C$. defragrans $\Delta$ geoAcomp. One explanation for the reduced growth is a higher steady-state level of

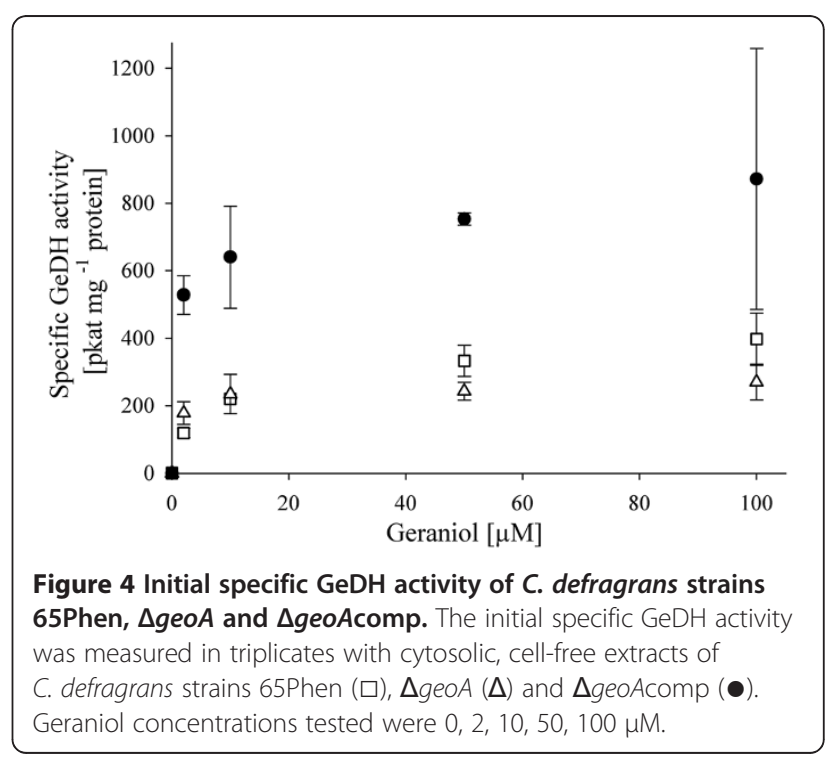


geraniol in the cell causing toxic effects. These observations together with reduced geranic acid formation demonstrate clearly a participation of $\mathrm{GeDH}$ in the anaerobic degradation of $\beta$-myrcene. However, the geo $A$ deletion is not mortal. A second $\mathrm{GeDH}$ activity is present in soluble extracts. This suggests a need for both $\mathrm{GeDHs}$ to balance the geraniol formation by oxidation during fast growth of the wild type.

The physiological characterization regarding growth with acyclic and cyclic monoterpenes exhibited an unexpected effect of the ldi deletion that caused a phenotype dependent on the substrate structure in $C$. defragrans $\Delta l d i$ : the cyclic monoterpenes $\alpha$-phellandrene and limonene were metabolized, but not the acyclic $\beta$-myrcene. Thus, the degradation of the acyclic $\beta$-myrcene required the activity of a linalool dehydratase-isomerase that was not necessary for the degradation of cyclic monoterpenes. This observation indicates for the presence of a second hydrocarbon activating system in C. defragrans.

\section{Methods}

\section{Bacterial strains and plasmids}

Table 3 described plasmids, $C$. defragrans strain 65Phen (wild type as well as derivatives) and E. coli strains used in this study. In course of the text, abbreviations are: i)
C. defragrans 65Phen-RIF is equivalent to $C$. defragrans RIF; ii) C. defragrans 65Phen-RIF $\Delta l d i$ is equivalent to C. defragrans $\Delta l d i$; iii) C. defragrans 65Phen-RIF $\Delta l d i$ comp is equivalent to $C$. defragrans $\Delta$ ldicomp; iv) C. defragrans 65Phen-RIF $\triangle g e o A$ is equivalent to C. defragrans $\triangle g e o A ; \mathrm{v})$ C. defragrans 65Phen-RIF $\triangle g e o A-$ compgeo $A$ is equivalent to $C$. defragrans $\triangle$ geoAcomp.

\section{Culturing conditions and growth media}

E. coli strains were cultured according to established methods [66]. For propagation of plasmids, additional antibiotics were supplemented in the indicated concentrations [66]. Maintenance and growth experiments in liquid cultures with $C$. defragrans 65Phen and mutants were performed as described previously [40]. Growth in liquid cultures was monitored by turbidity measurements at $660 \mathrm{~nm}$.

Minimal medium for plates contained $50 \mathrm{mM}$ sodium acetate in medium solidified with $18 \mathrm{~g} / \mathrm{L}$ agar and additionally buffered with $50 \mathrm{mM}$ HEPES, $\mathrm{pH}$ 7.2. Incubation took place in anaerobic jars for 4 to 5 days under $\mathrm{N}_{2}$ atmosphere at $28^{\circ} \mathrm{C}$. Biomass production of C. defragrans strains was performed according to [46].

Antibiotics were used at following concentrations (unless indicated otherwise): $50 \mu \mathrm{g} / \mathrm{mL}$ ampicillin, $50 \mu \mathrm{g} / \mathrm{mL}$

\section{Table 3 Strains and plasmids used in this study}

\begin{tabular}{|c|c|c|}
\hline Strains or plasmids & Genotype, markers and further characteristics & Source/reference \\
\hline \multicolumn{3}{|l|}{ Strains } \\
\hline \multicolumn{3}{|l|}{ E. coli } \\
\hline S17-1 & Thi, pro, hsdR, recA with RP4-2[Tc::Mu-Km::Tn7] & [63] \\
\hline One Shot ${ }^{\circledR} T o p 10$ & $\begin{array}{l}\text { F- } m c r A \Delta \text { (mrr-hsdRMS-mcrBC) } \varphi 80 / a c Z \Delta M 15 \Delta / a c X 74 \text { recA1 } \\
\left.\text { araD139 } \Delta \text { (araleu) } 7697 \text { galU gal/K rpsL (Str }{ }^{R}\right) \text { endA1 nupG }\end{array}$ & Invitrogen \\
\hline \multicolumn{3}{|l|}{ C. defragrans } \\
\hline 65Phen & Wild type & {$[40]$} \\
\hline 65Phen-RIF ${ }^{\mathrm{a}}$ & $\mathrm{Ra}^{\mathrm{R}}$ & This study \\
\hline 65Phen-RIF $\Delta / d i^{b}$ & $\mathrm{Ra}^{\mathrm{R}}, \Delta / d i$ & This study \\
\hline 65Phen-RIF $\Delta /$ dicomp $^{c}$ & $\mathrm{Ra}^{\mathrm{R}}, \Delta / d i, \mathrm{pBBR} 1 \mathrm{MCS}-4 / d i$ & This study \\
\hline 65Phen-RIF $\Delta g e o A^{\mathrm{d}}$ & $\mathrm{Ra}^{\mathrm{R}}, \triangle g e o A$ & This study \\
\hline 65Phen-RIF $\Delta$ geoAcomp & $\mathrm{Ra}^{\mathrm{R}}, \triangle g e o A, \mathrm{pBBR} 1 \mathrm{MCS}-2 g e \mathrm{~A}$ & This study \\
\hline \multicolumn{3}{|l|}{ Plasmids } \\
\hline pCR4-TOPO & $\mathrm{Am}^{\mathrm{R}}, \mathrm{Km}^{\mathrm{R}}, \mathrm{lacZa}$ & Invitrogen \\
\hline pK19mobsacB & $\mathrm{Km}^{\mathrm{R}}$, sacB modified from B. subtilis, lacZa & [64] \\
\hline pK19mobsacB $\Delta / d i$ & $\mathrm{Km}^{\mathrm{R}}$, sacB modified from B. subtilis, lacZa, ORF25, ORF27 & This study \\
\hline pK19mobsacB $\Delta$ geoA & $\mathrm{Km}^{\mathrm{R}}$, sacB modified from B. subtilis, lacZa, ORF29-30, ORF32 & This study \\
\hline pBBR1MCS-4 & $A m^{R}, m o b, l a c Z a$ & {$[65]$} \\
\hline pBBR1MCS-4/di & $\mathrm{Am}^{\mathrm{R}}, \mathrm{mob}, \mathrm{lacZa}, l d i$ & This study \\
\hline PBBR1MCS-2 & $\mathrm{Km}^{\mathrm{R}}, \mathrm{mob}, \mathrm{lacZa}$ & {$[65]$} \\
\hline pBBR1MCS-2geoA & $\mathrm{Km}^{\mathrm{R}}$, mob, lacZa, geoA & This study \\
\hline
\end{tabular}

a abbreviated in course of the text to $C$. defragrans RIF, ${ }^{\mathrm{b}}$ abbreviated to $C$. defragrans $\Delta / d i,{ }^{c}$ abbreviated to $C$. defragrans $\Delta /$ dicomp, ${ }^{\text {d }}$ abbreviated to $C$. defragrans $\triangle g e o A,{ }^{e}$ abbreviated to C. defragrans $\triangle$ geoAcomp. 
kanamycin, and $150 \mu \mathrm{g} / \mathrm{mL}$ rifampicin. Plating efficiency was determined by plating decading dilutionto-extinction series of cell suspensions with known optical density (OD) at $660 \mathrm{~nm}$ in duplicates.

\section{Preparation and manipulation of genetic material}

Genomic DNA was isolated from $C$. defragrans 65Phen using the DNeasy Tissue Kit (Quiagen, Hilden, Germany). Plasmid DNA was isolated from E. coli strains and C. defragrans 65Phen using mini-plasmid preparation kits (Quiagen). Gel-excised PCR products and plasmid fragments were purified with the QIAquick gel extraction kit (Quiagen).

PCR amplification was usually performed using Taq polymerase (Promega, Madison, USA). For cloning purposes a mixture of Taq polymerase and a thermostable polymerase with proofreading activity (Fermentas, St. Leon Rot, Germany) were applied.

\section{Transcription analyses with Reverse Transcriptase-PCR}

Preparation of total RNA from C. defragrans strains after growth on $\alpha$-pellandrene was performed with RNeasy Mini Kit (Qiagen) according to manufacturer's instructions, followed by cDNA synthesis using the Revert Aid ${ }^{\text {TM }}$ First Strand cDNA Synthesis Kit (Fermentas). For transcriptional analyses, RT-PCR was performed with 35 cycles with primer pairs listed in Table 4. Negative controls included RT-PCR without reverse transcriptase. Table 4 lists primers used for the different amplification purposes.

\section{Ligation and transformation of plasmid constructs}

Subcloning of PCR products into pCR4-TOPO ${ }^{\circledR}$ vector (Invitrogen, Darmstadt, Germany) was performed corresponding to manufacturer's instructions. PCR products with inserted restriction sites and purified plasmids were digested with the appropriate restriction enzymes and separated by gel electrophoresis. Both digested plasmids and PCR products were gel excised and purified. For ligation reactions, an insert-vector ratio of $1: 1,3: 1$ or 10:1 was chosen. To this mixture, T4-ligase buffer $(1 \mathrm{x})$, ATP $(25 \mu \mathrm{M})$ and T4-ligase $(2.5 \mathrm{U})$ were added. Incubation was for $12-16 \mathrm{~h}$ at $12^{\circ} \mathrm{C}$. Transformation of 5 or $10 \mu \mathrm{L}$ of the ligation reaction to chemical competent E. coli strains S17-1 or Top10 was performed as described [67]. Single colonies growing on selective solid medium were picked and screened for the correct insert size by PCR applying M13 or T7 primers. Plasmids of positive tested clones were purified and served as sequencing templates.

\section{Construction of suicide plasmids}

The 5 ' - and $3{ }^{`}$-flanking regions of $l d i$ or geo $A$ and the start and stop codons of the deleted gene separated by an appropriate specific restriction site were inserted into the suicide vector pK19mobsacB [64]. Oligonucleotide sequences are listed in Table 4.

Initially, the flanking regions were amplified from genomic $C$. defragrans 65Phen DNA with primers adding restriction enzyme sites to the PCR-product. The 5 -flanking region to the $l d i$ was obtained with the primer pair ORF25_EcoRI_F and ORF25_XhoIATG_R. During amplification of the 3 '-flanking region with primer pairs ORF27_XhoI_TAA_F and ORF27_HindIII_R difficulties occurred due to a terminator structure in the genome sequence that was solved with a nested PCR approach. A $2.2 \mathrm{~kb}$ amplicon comprising ORF 27 was obtained with the primer pair p27plus_F and p27plus_R that served as template for the initial named primer with an increased initial denaturation time (from $4 \mathrm{~min}$ to $10 \mathrm{~min}$ ). Sequencing of the $763 \mathrm{bp}$ amplicon revealed a base exchange at position 373 from guanine to adenine causing an amino acid replacement from proline to threonine. This shift was revoked by a site directed mutagenesis approach using primer p27_ mismatch_F and p27_mismatch_R in combination with ORF27_XhoI_TAA_F and ORF27_HindIII_R, respectively [68]. The particular amplicons were bond to each other in another reaction with the exterior primer pair. The 5 -flanking region of the geo $A$ was obtained with the primer pair ORF2930_XbaI_F \& ORF2930_XhoI_R and the geoA 3'-flanking region ORF32_XhoI_F \& ORF32_HindIII_R.

The obtained products were subcloned into pCR4TOPO (Invitrogen, Darmstadt, Germany) and yielded pCR4-ORF25, pCR4-ORF27, pCR4-ORF2930 and pCR4ORF32. The sequence correctness of these constructs was confirmed by sequencing and restriction digests.

Subcloning vectors were double digested with the prevailing added recognitions site for restriction enzymes. The flanking regions were excised, purified and ligated via a three-piece-ligation into the suicide vector pK19mobsacB [64]. Sequencing of the obtained plasmids $\mathrm{pK} 19 \mathrm{mobsacB} \Delta l d i$ and $\mathrm{pK} 19 \mathrm{mobsacB} \Delta g e o A$ was performed to ensure correct sequence of the flanking regions including the start and stop codons of the deleted genes.

\section{Construction of complementation plasmids}

For construction of the in trans vector both, the ldi and the geoA was amplified from genomic DNA of $C$. defragrans 65Phen with primer pair encompassing the entired ORF, i.e. for the $l d i$ primer pair $l d i \_E c o R I ~ \& l d i \_B g l I I$, and for geoA geoA_XbaI_F \& geoA_HindIII_R (Table 4). $\mathrm{Via}$ the added restriction enzyme recognition sites the amplicon was inserted into the multiple cloning site of two different derivatives of the broad-host range vector pBBR1MCS [69]. For confirmation of correct gene 


\begin{tabular}{|c|c|c|c|}
\hline Primer & Sequence $\left(5^{`} \rightarrow 3^{\prime}\right)$ & Amplicon (bp) & Target gene \\
\hline \multicolumn{4}{|l|}{ Idi deletion construct } \\
\hline \multicolumn{4}{|l|}{ (pK19mobsacB } \\
\hline ORF25_ECORI_F & TCGTAGAATTCCATGCCTGCGCACGCTGATG & 1307 & ORF25 \\
\hline ORF25_Xhol_ATG_R & GAGACTCGAGATGTTCAGTCGCATGTCGTCT & & \\
\hline ORF27_Xhol_TAA_F & TATACTCGAGTAAGGGGGACGCGGCGGCCTG & 763 & ORF27 \\
\hline ORF27_HindIII_R & TCGTAAAGCTTATGGACGACGGCACATGGA & & \\
\hline $\mathrm{p} 27+\ldots \mathrm{F}$ & ACGAAGCCGAGCATGCCCAC & 2199 & encompassing \\
\hline $\mathrm{p} 27+{ }_{2} \mathrm{R}$ & AGCAGCAGGCCGACGTGTTC & & ORF27 \\
\hline p27mismatch_F & CGCCCGGTTCGAGGAAGG & - & nucleotide \\
\hline p27mismatch_R & CCCTTCCTCGAACCGGGCG & & exchange \\
\hline \multicolumn{4}{|l|}{ geoA deletion construct } \\
\hline \multicolumn{4}{|l|}{ (pK19mobsacB) } \\
\hline ORF2930_Xbal_F & TCTAGACCACCAGGGCGCATGCTTCAGTT & 1749 & ORF2930 \\
\hline ORF2930_Xhol_R & CTCGAGTGAGCAGGGCGCGACTCC & & \\
\hline ORF32_Xhol_F & CTCGAGCATCGTTGAGTGTCTCCTGGTTG & 1712 & ORF32 \\
\hline ORF32_HindIII_R & 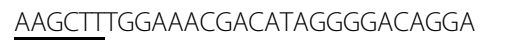 & & \\
\hline \multicolumn{4}{|c|}{ Control of Idi or geoA deletion } \\
\hline Idi_F & CGCCACCACCGAGGACTATTTC & 432 & Idi \\
\hline Idi_R & AGGTGGGCATGCTCGGCTTCGTA & & \\
\hline ORF25_401_F & GAAGGTGCGCGGCAAGGAATA & $2463^{a} /$ & ORF25-27 \\
\hline ORF27_2005_R & CATGGACAGCGGCACACGGGCAA & $1269^{b}$ & \\
\hline geoA_260_F & ACCGGGTCGTGCTGTCCTTCAAT & 284 & geoA \\
\hline geoA_527_R & CGCGCCGGTCTGGATGC & & \\
\hline ORF30_30967_F & CCAGACGCCGCCGATGATGAAGAG & $1904^{\mathrm{a}} /$ & ORF30-32 \\
\hline ORF32_32822_R & TATCTGAACAAGCCCGAACTGACC & $740^{c}$ & \\
\hline \multicolumn{4}{|c|}{ Idi complementation construct } \\
\hline \multicolumn{4}{|l|}{ (pBBR1MCS-4) } \\
\hline Idi_EcoRI_F & TGCGGAATTCATGCGGTTCACATTG & 1206 & Idi \\
\hline Idi_Bgll|_R & CGCGAGATCTTTATTTCCCTGCGA & & \\
\hline \multicolumn{4}{|c|}{ geoA complementation construct } \\
\hline \multicolumn{4}{|l|}{ (pBBR1MCS-2) } \\
\hline geoA_Xbal_F & AATCTAGACGCCCTGCTCAGAACAC & 1290 & geoA \\
\hline geoA_HindllI_R & GAGCAAGCTTACCCTGCGCAAGCAGTTC & & \\
\hline \multicolumn{4}{|c|}{ Control of adjacent gene transcription } \\
\hline ORF25_254_F & CCCACCGGCTTCTCGTAGTC & 535 & ORF25 \\
\hline ORF25_788_R & GCAAGGGCCTGGGCGTGATGTC & & \\
\hline ORF27_28_F & CATGGACAGCGGCACACGGGCAA & 350 & ORF27 \\
\hline ORF27_377_R & CAGTGGACCTCGCCGTGGAAAT & & \\
\hline ORF30_315_F & CGCGGGCGGGATGGTGAT & 411 & ORF30 \\
\hline ORF30_725_R & CGGGCGGCGGGTTCGTT & & \\
\hline ORF32_608_F & CCTGGCGGCCGGACGACAT & 462 & ORF32 \\
\hline ORF32_1069_R & CGCCGGAAGGGGAAACGAC & & \\
\hline
\end{tabular}

Restriction sites are underlined. Oligonucleotide primers derived from annotated $50 \mathrm{~kb}$ contig of $C$. defragrans 65Phen (Acc. no. FR669447.2) [47]. ${ }^{a}$ wild type; ${ }^{\mathrm{b}} \mathrm{C}$. defragrans $\Delta \mathrm{ldi}$, ${ }^{\mathrm{C}} \mathrm{C}$. defragrans $\Delta$ geoA. 
insertion the obtained plasmids pBBR1MCS-4ldi and pBBR1MCS-2geoA was sequenced.

\section{Conjugational plasmid transfer}

The donor strain, an overnight culture of E. coli S17-1 carrying the appropriate plasmid, and the recipient C. defragrans RIF were grown to late exponential phase and were mixed in several ratios $(1: 1,1: 5,1: 10)$ in a total volume of $20 \mu \mathrm{L}$ and spread as a single drop on minimal agar. After incubation for $24 \mathrm{~h}$ at $28^{\circ} \mathrm{C}$ under oxic conditions the bacteria were resuspended in $1 \mathrm{~mL}$ liquid minimal medium. Dilution-to-extinction series were streaked out onto solid minimal medium supplemented with kanamycin and rifampicin and anaerobically incubated at $28^{\circ} \mathrm{C}$ for four days.

\section{Preparation of cell-free extracts and determination of enzyme activities}

Soluble extract preparations of $C$. defragrans strains 65Phen, $\triangle g e o A$ and $\triangle g e o A c o m p$ were performed as described [46]. The geraniol dehydrogenase activity was monitored in a standard assay following the reduction of $\mathrm{NAD}^{+}$to $\mathrm{NADH}$ at $340 \mathrm{~nm}$ as described [47]. Equal total protein amounts were applied as certified in a 200$\mu \mathrm{l}$ aliquot by the method of Bradford [70] with BSA as standard protein; concentrations were corrected for the unusual high binding of the Coomassie stain to albu$\min [71]$.

\section{Chemical analyses of biomass, educts and products}

Nitrate and nitrite was measured by HPLC as described by [72]. Based on the fact that protein accounts for $50 \%$ of the cell mass, the Bradford assay was applied in duplicates with two different dilutions to determine the total biomass yield [72]. Geranic acid formation was assayed in liquid cultures of $C$. defragrans strains after confirmed nitrate depletion (Merckoquant ${ }^{\circledR}$ test strips (Merck, Darmstadt, Germany)). $10 \mathrm{~mL}$ cell culture was acidified with $\mathrm{H}_{3} \mathrm{PO}_{4}$ (final concentration $0.1 \mathrm{M}$ ) and extracted with tert-butyl methyl ether in a 1:0.4 ratio (two biological replicates per strain). The ether extract was extracted with $0.1 \mathrm{M} \mathrm{NaOH}(1: 1)$ and the aqueous phase was subjected twice to reverse-phase HPLC on a Nucleodur ${ }^{\circledR}$ C18 ISIS (4.6 mm $\times 250 \mathrm{~mm}$, Macherey Nagel, Düren, Germany). Separation of the organic acid was performed with $1 \mathrm{mM}$ $\mathrm{H}_{3} \mathrm{PO}_{4}$ in an isocratic water-acetonitrile eluent $(45 / 55(\mathrm{v} / \mathrm{v}))$ at $1 \mathrm{~mL} / \mathrm{min}$ and $25^{\circ} \mathrm{C}$. Intermediary, the column was cleaned with water-acetonitrile $(20 / 80(\mathrm{v} / \mathrm{v}))$. UV detection was performed at $215 \mathrm{~nm}$.

\section{Additional file}

Additional file 1: Additional Material.

\section{Competing interest}

The authors declare that they have no competing interests.

\section{Authors' contributions}

$A D$ isolated the rifampicin resistant $C$. defragrans strains and assayed the conjugation frequencies. AD constructed pK19mobsacB $\triangle$ geo $A$ and obtained C. defragrans $\Delta g e o A$. FL obtained C. defragrans $\Delta g e o A$ and $\Delta /$ di deletion mutants and constructed the pBBR1MCS-2 derivates. FL performed all the physiological experiments. $\mathrm{FL}$ and $\mathrm{JH}$ analysed the physiological experiments and wrote the manuscript. All authors read and approved the final manuscript.

\section{Acknowledgements}

We thank Robert Marmulla and Maria Grünberg for their technical assistance in the construction of $C$. defragrans $\Delta / d i$. This study was financed by the Max Planck Society.

Received: 20 February 2012 Accepted: 21 August 2012

Published: 4 September 2012

\section{References}

1. Lathiere J, Hauglustaine DA, Friend AD, De Noblet-Ducoudrè N, Viovy N, Folberth GA: Impact of climate variability and land use changes on global biogenic volatile organic compound emissions. Atmos Chem Phys 2006, 6:2129-2146.

2. Kesselmeier J, Staudt M: Biogenic volatile organic compounds (VOC): an overview on emission, physiology and ecology. J Atmos Chem 1999, 33:23-88.

3. Dudareva N, Negre F, Nagegowda DA, Orlova I: Plant volatiles: recent advantages and future perspectives. Crit Rev Plant Sci 2006, 25:417-440.

4. Sharkey TD, Wiberly AE, Donohue AR: Isoprene emission from plants: why and how. Ann Bot 2008, 101:5-18.

5. Smolander A, Ketolab RA, Kotiahod T, Kanervaa S, Suominene K, Kitunena V: Volatile monoterpenes in soil atmosphere under birch and conifers: effects on soil N transformations. Soil Biol Biochem 2006, 38:3436-3442.

6. Hayward S, Muncey RJ, James AE, Halsall CJ, Hewitt CN: Monoterpene emissions from soil in a Sitka spruce forest. Atmos Environ 2001, 35:4081-4087

7. Lin C, Owen SM, Penuelas J: Volatile organic compounds in the roots and rhizosphere of pinus spp. Soil Biol Biochem 2007, 39:951-960.

8. Ramirez KS, Lauber $\mathrm{CL}$, Fierer N: Microbial consumption and production of volatile organic compounds at the soil-litter interface. Biogeochemistry 2010, 99:97-107.

9. Vokou D, Douvli P, Blionis GJ, Halley JM: Effects of monoterpenoids, acting alone or in pairs, on seed germination and subsequent seedling growth. J Chem Ecol 2003, 29:2281-2301.

10. Leff JW, Fierer N: Volatile organic compound (VOC) emissions from soil and litter samples. Soil Biol Biochem 2008, 40:1629-1636.

11. Vokou D, Chalkos D, Karamanlidou G, Yiangou M: Activation of soil respiration and shift of the microbial population balance in soil as a response to lavendula stoechas essential oil. J Chem Ecol 2002, 28:755-768.

12. Ajikumar PA, Tyo K, Carlsen S, Mucha O, Phon TH, Stephanopoulos G: Terpenoids: opportunities for biosynthesis of natural product drugs using engineered microorganisms. Mol Pharm 2008, 5:167-190.

13. Flesch G, Rohmer M: Prokaryotic hopanoids: the biosynthesis of the bacteriohopane skeleton - formation of isoprenic units from two distinct acetate pools and a novel type of carbon/carbon linkage between a triterpene and D-ribose. Eur J Biochem 1988, 175:405-411.

14. Lichtenthaler HK, Rohmer M, Schwender J: Two independent biochemical pathways for isopentenyl diphosphate and isoprenoid biosynthesis in higher plants. Physiol Plant 1997, 101:643-652.

15. Aharoni A, Giri AP, Deuerlein S, Griepink F, de Kogel WJ, Verstappen FWA, Verhoeven HA, Jongsma MA, Schwab W, Bouwmeester HJ: Terpenoid metabolism in wildtype and transgenic arabidopsis plants. Plant Cell 2003, $15: 2866-2884$

16. Hampel D, Mosandl A, Wüst M: Biosynthesis of mono- and sesquiterpenes in carrot roots and leaves (Daucus carota L.): metabolic cross talk of cytosolic mevalonate and plastidial methylerythritol phosphate pathways. Phytochemistry 2005, 66:305-311. 
17. Adams TB, Gavin CL, McGowen MM, Waddell WJ, Cohen SM, Feron VJ, Marnett LJ, Munro IC, Portoghese PS, Rietjens IMCM, Smith RL: The FEMA GRAS assessment of aliphatic and aromatic terpene hydrocarbons used as flavor ingredients. Food Chem Toxicol 2011, 49:2471-2494.

18. Chen W, Viljoen AM: Geraniol - a review of a commercially important fragrance material. S Afr J Bot 2010, 76:643-651.

19. Dhavalikar RS, Rangachari PN, Bhattacharyya PK: Microbiological transformations of terpenes. IX. Pathways of degradation of limonene in a soil pseudomonad. Indian J Biochem 1966, 3:158-164.

20. Seubert W: Degradation of isoprenoid compounds by microorganisms 1 . Isolation and characterization of an isoprenoid-degrading bacterium, pseudomonas citronellolis n. sp. J Bacteriol 1960, 79:426-434.

21. Shukla OP, Bhattacharyya PK: Microbiological transformation of terpenes. $\mathrm{XI}$. Pathways of degradation of $\alpha$ - and $\beta$-pinenes in a soil pseudomonad (PL-strain). Ind J Biochem 1968, 5:92-101.

22. Cantwell SG, Lau EP, Watt DS, Fall R: Biodegradation of acyclic isoprenoids by pseudomonas species. J Bacteriol 1978, 135:324-333.

23. Förster-Fromme K, Höschle B, Mack C, Bott M, Armbruster W, Jendrossek D: Identification of genes and proteins necessary for catabolism of acyclic terpenes and leucine/isovalerate in pseudomonas aeruginosa. Appl Environ Microbiol 2006, 72:4819-4828.

24. Iurescia S, Marconi M, Tofani D, Gambacorta A, Paterno A, Devirgiliis C, van der Werf $M$, Zennaro $E$ : Identification and sequencing of $\beta$-myrcene catabolism genes from pseudomonas sp. strain M1. Appl Environ Microbiol 1999, 65:2871-2876.

25. Madyastha KM, Bhattacharyya PK, Vajdyanathan CS: Metabolism of a monoterpene alcohol, linalool, by a soil pseudomonad. Can J Microbiol 1977, 23:230-239.

26. Prakash O, Kumari K, Lal R: Pseudomonas delhiensis sp. nov., from a fly ash dumping site of a thermal power plant. Int J Syst Evol Microbiol 2007, 57:527-531.

27. Tudroszen NJ, Kelly DP, Millis NF: a-Pinene metabolism by pseudomonas putida. Biochem J 1977, 168:315-318.

28. Vandenbergh PA, Wright AM: Plasmid involvement in acyclic isoprenoid metabolism by pseudomonas putida. Appl Environ Microbiol 1983, 45:1953-1955.

29. Chang HC, Oriel PJ: Bioproduction of perillyl alcohol and related monoterpenes by isolates of bacillus stearothermophilus. J Food Sci 1994 59:660-662.

30. van der Werf M, Swarts HJ, de Bont JAM: Rhodococcus erythropolis DCL14 contains a novel degradation pathway for limonene. Appl Environ Microbiol 1999, 65:2092-2102.

31. Yang EJ, Park YJ, Chang HC: Cloning of four genes involved in limonene hydroxylation from enterobacter cowanii 6 L. J Microbiol Biotechnol 2007, 17:1169-1176.

32. Best DJ, Floyd NC, Magalhaes A, Burfield A, Rhodes PM: Initial enzymatic steps in the degradation of a-pinene by pseudomonas fluorescens NCIMB 11671. Biocatalysis 1987, 1:147-159.

33. Griffiths ET, Bociek SM, Harries PC, Jeffcoat R, Sissons DJ, Trudgill PW: Bacterial metabolism of a-pinene: pathway from a-pinene oxide to acyclic metabolites in nocardia sp. strain P18.3. J Bacteriol 1987, 169:4972-4979.

34. Marostica MR Jr, Pastore GM: Limonene and its oxyfunctionalized compounds: biotransformation by microorganisms and their role as functional bioactive compounds. Food Sci Biotechnol 2009 18:833-841.

35. Linares D, Fontanille $P$, Larroche C: Exploration of a-pinene degradation pathway of pseudomonas rhodesiae CIP 107491. Application to novalic acid production in a bioreactor. Food Res Int 2009, 42:461-469.

36. Trudgill PW: Microbial metabolims of monoterpenes - recent developments. Biodegradation 1990, 1:93-105.

37. Ullah AJH, Murray RI, Bhattacharyya PK, Wagner GC, Gunsalus IC: Proteincomponents of a cytochrome P-450 linalool 8-methyl hydroxylase. J Biol Chem 1990, 265:1345-1351.

38. van der Werf MJ, Keijzer PM, van der Schaft PH: Xanthobacter sp C20 contains a novel bioconversion pathway for limonene. J Biotechnol 2000 84:133-143.

39. Harder J, Probian C: Microbial degradation of monoterpenes in the absence of molecular oxygen. App/ Environ Microbiol 1995, 61:3804-3808.

40. Foss $\mathrm{S}$, Heyen $U$, Harder J: Alcaligenes defragrans sp. nov., description of four strains isolated on alkenoic monoterpenes ((+)-menthene, a-pinene, 2-carene, and a-phellandrene) and nitrate. Syst Appl Microbio/ 1998, 21:237-244.

41. Kämpfer P, Denger K, Cook AM, Lee ST, Jäckel U, Denner EBM, Busse HJ: Castellaniella gen. nov., to accommodate the phylogenetic lineage of alcaligenes defragrans, and proposal of castellaniella defragrans gen. nov., comb. nov. and castellaniella denitrificans sp. nov. Int J Syst Evol Microbiol 2006, 56:815-819.

42. Heyen $U$, Harder J: Cometabolic isoterpinolene formation from isolimonene by denitrifying alcaligenes defragrans. FEMS Microbiol Lett 1998, 169:67-71.

43. Heyen U, Harder J: Geranic acid formation, an initial reaction of anaerobic monoterpene metabolism in denitrifying alcaligenes defragrans. Appl Environ Microbiol 2000, 66:3004-3009.

44. Aguilar JA, Zavala AN, Díaz-Pérez C, Cervantes C, Díaz-Pérez AL, Campos-García J: The atu and liu clusters are involved in the catabolic pathways for acyclic monoterpenes and leucine in Pseudomonas aeruginosa. Appl Environ Microbiol 2006, 72:2070-2079.

45. Förster-Fromme K, Jendrossek D: Catabolism of citronellol and related acyclic terpenoids in pseudomonads. Appl Microbiol Biotechnol 2010, 87:859-869.

46. Brodkorb D, Gottschall M, Marmulla R, Lüddeke F, Harder J: Linaloo dehydratase-isomerase, a bifunctional enzyme in the anaerobic degradation of monoterpenes. J Biol Chem 2010, 285:30406-30442.

47. Lüddeke F, Wülfing A, Timke M, Germer F, Weber J, Dikfidan A, Rahnfeld T, Linder D, Meyerdierks A, Harder J: Geraniol dehydrogenase and geranial dehydrogenase induced in the anaerobic monoterpene degradation of castellaniella defragrans. Appl Environ Microbiol 2012, 78:2128-2136.

48. Lüddeke F, Harder J: Enantiospecific (S)-(+)-linalool formation from $\beta$-myrcene by linalool dehydratase-isomerase. Z Naturforsch C Biosci 2011, 66c:409-412.

49. Riveros-Rosas H, Julian-Sanchez A, Villalobos-Molina R, Pardo JP, Pina E: Diversity, taxonomy and evolution of medium-chain dehydrogenase/ reductase superfamily. Eur J Biochem 2003, 270:3309-3334

50. Duetz WA, Bouwemeester $\mathrm{H}$, van Beilen JB, Witholt B: Biotransformation of limonene by bacteria, fungi, yeasts, and plants. Appl Microbiol Biotechnol 2003, 61:269-277.

51. Speelmans G, Bijlsma A, Eggink G: Limonene bioconversion to high concentrations of a single and stable product, perillic acid, by a solvent-resistant pseudomonas putida strain. Appl Microbiol Biotechnol 1998, 50:538-544.

52. van Beilen JB, Holtackers R, Lüscher D, Bauer U, Witholt B, Duetz WA Biocatalytic production of perillyl alchohol from limonene using a novel mycobaterium sp. cytochrome P450 alkane hydroxlase expressed in pseudomonas putida. Appl Environ Microbiol 2005, 71:173-1744

53. Kniemeyer $\mathrm{O}$, Heider J: Ethylbenzene dehydrogenase, a novel hydrocarbon-oxidizing molybdenum/iron-sulfur/heme enzyme. J Biol Chem 2001, 276:21381-21386.

54. Chiang YR, Ismail W, Müller M, Fuchs G: Initial steps in the anoxic metabolism of cholesterol by the denitrifying sterolibacterium denitrificans. J Biol Chem 2007, 282:13240-13249.

55. Santos PM, Sa-Correia I: Adaptation to ß-myrcene catabolism in Pseudomonas sp. M1: an expression proteomic analysis. Proteomics 2009 9:5101-5111.

56. Di Pasqua R, Betts G, Hoskins N, Edwards M, Ercolini D, Mauriello G: Membrane toxicity of antimicrobial compounds from essential oils. J Agric Food Chem 2007, 55:4863-4870.

57. Sikkema J, de Bont JAM, Poolman B: Mechanisms of membrane toxicity of hydrocarbons. FEMS Microbiol Rev 1995, 59:201-222.

58. Reid MF, Fewson CA: Molecular characterization of microbial alcohol dehydrogenases. Crit Rev Microbiol 1994, 2:13-56.

59. Chattopadhyay A, Förster-Fromme K, Jendrossek D: PQQ-dependent alcohol dehydrogenase (QEDH) of pseudomonas aeruginosa is involved in catabolism of acyclic terpenes. J Bas Microbiol 2010, 50:119-124.

60. Malone VF, Chastain AJ, Ohlsson JT, Poneleit LS, Nemecek-Marshall M, Fall R Characterization of a pseudomonas putida allylic alcohol dehydrogenase induced by growth on 2-methyl-3-buten-2-ol. Appl Environ Microbiol 1999, 65:2622-2630

61. Sakurai $M$, Tohda $H$, Kumagai $H$, Giga-Hama $Y$ : A distinct type of alcohol dehydrogenase, adh4 $4^{+}$, complements ethanol fermentation in an adh1-deficient strain of Schizosaccharomyces pombe. FEMS Yeast Res 2004, 4:649-654 
62. lijima Y, Wang G, Fridman E, Pichersky E: Analysis of the enzymatic formation of citral in the glands of sweet basil. Arch Biochem Biophys 2006, 448:141-149.

63. Simon R, Priefer $U$, Puhler A: A broad host range mobilization system for in vivo genetic engineering: transposon mutagenesis in gram-negative bacteria. Nat Biotechnol 1983, 1:784-791.

64. Schäfer A, Tauch A, Jager W, Kallnowski J, Thierbach G, Pühler A: Small mobilizable multi-purpose cloning vectors derived from the escherichia coli plasmids pK18 and pK19: selection of defined deletions in the chromosome of corynebacterium glutamicum. Gene 1994, 145:69-73.

65. Kovach ME, Elzer PH, Hill DS, Robertson GT, Farris MA, Roop RM, Peterson KM: Four new derivatives of the broad host range cloning vector pBBR1MCS, carrying different antibiotic resistance cassettes. Gene 1995, 166:175-176.

66. Sambrook J, Russel DW: Molecular cloning: a laboratory manual, ed 3. Cold Spring Harbor: Cold Spring Harbor laboratory Press; 2001.

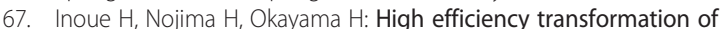
escherichia coli with plasmids. Gene 1990, 96:23-28.

68. Higuchi R, Krummel B, Saiki RK: A general method of in vitro preparation and specific mutagenesis of DNA fragments: study of protein and DNA interactions. Nucleic Acids Res 1988, 16:7351-7367.

69. Kovach ME, Phillips RW, Elzer PH, Roop RM, Peterson KM: pBBR1MCS: a broad-host-range cloning vector. Biotechniques 1994, 16:800-802.

70. Bradford MM: A rapid and sensitive method for the quantification of microgram quantities of protein utilizing the principle of protein-dye binding. Anal Biochem 1976, 72:248-254.

71. Biorad: BioRad Protein Assay. Instruction Manual. Munich: BioRad; 1994.

72. Harder J, Probian C: Anaerobic mineralization of cholesterol by a novel type of denitrifying bacterium. Arch Microbiol 1997, 167:269-274.

doi:10.1186/1471-2180-12-192

Cite this article as: Lüddeke et al:: Physiology of deletion mutants in the anaerobic $\beta$-myrcene degradation pathway in Castellaniella defragrans. BMC Microbiology 2012 12:192.

\section{Submit your next manuscript to BioMed Central and take full advantage of:}

- Convenient online submission

- Thorough peer review

- No space constraints or color figure charges

- Immediate publication on acceptance

- Inclusion in PubMed, CAS, Scopus and Google Scholar

- Research which is freely available for redistribution 